\title{
Implantação da Companhia Siderúrgica do Atlântico na Baía de Sepetiba-RJ
}

\author{
Patrícia Santiago Pato (UERJ-FFP) \\ Universidade Estadual do Rio de Janeiro \\ patricia_patorj@yahoo.com.br
}

\section{Resumo}

A Companhia Siderúrgica do Atlântico (CSA) é uma parceria da Companhia Vale do Rio Doce com a alemã Thyssenkrupp, cujo investimento é da ordem de $€$ 5,2 bilhões de euros. A produção prevista é de cinco milhões de toneladas de placas de aço por ano, resultando no aumento de $40 \%$ das exportações brasileiras no setor siderúrgico.

A siderúrgica está localizada na região administrativa de Santa Cruz município do Rio de Janeiro na porção oeste da metrópole fluminense, nas margens da Baía de Sepetiba. A instalação da empresa na região consiste no maior investimento privado da América Latina e o empreendimento está numa localidade extremamente impactada por grandes empreendimentos como a Casa da Moeda e a White Martins e vários projetos novos a serem implementados como Porto Sudeste e a construção de um estaleiro de grande porte da Marinha do Brasil.

Este trabalho tem por objetivo investigar o processo de implantação do Complexo Siderúrgico do Atlântico (CSA) entre os anos de 2005 e 2010. A pesquisa encontra-se em fase de andamento. A metodologia utilizada conta com o apoio teórico do autor Carlos Vainer (1992) a partir do conceito de Grandes Projetos de Investimento. Os dados que serão apresentados foram desenvolvidos com base em pesquisas bibliográficas, imagens, mapas, depoimentos por parte da população, entre outros.

A empresa entrou em operação no dia 18 de junho de 2010 e a instalação está repercutindo em diversos problemas socioambientais como a expulsão de 75 famílias do Movimento Sem Terra e a criação de uma área de exclusão da pesca numa região que possui atividades econômicas como a pesca e o turismo.

Com a instalação dos empreendimentos previstos na região: as novas usinasCompanhia Siderúrgica do Atlântico (CSA) e a Companhia Siderúrgica Nacional (CSN), o Estado do Rio de Janeiro passará a ser o maior produtor de aço do país e um dos maiores da América Latina.

\section{Abstract}

\section{Deployment of the Company Atlantic in Sepetiba Bay-RJ}

The Steel Company of the Atlantic Ocean (CSA) is a partnership of Vale do Rio Doce Company with the german Thyssenkrupp, whose investment is of the order of $€ 5.2$ billion. The planned production and five million tons of steel slabs per year, resulting in an increase of $40 \%$ of the brazilian exports in the steel industry. 
The steel plant is located in the administrative region of Santa Cruz - city of Rio de Janeiro in western portion of the fluminense's metropolis on the banks of the Bay of Sepetiba.

The installation of the company in the region is the largest private investment in Latin America and the resort is a place highly impacted for large projects such as the Home of the Currency and the White Martins and several new projects to be implemented as a Southeast Port and the construction of a yard of large size of the Brazilian Navy. Complex

This work has for objective to investigate the process of implementation of the

Steel of the Atlantic (CSA) between the years 2005 and 2010. The methodology used with the support of theoretical author Carlos Vainer (1992) from the concept of Large Investment Projects. The data that will be presented were developed on the basis of bibliographical searches, images, maps, statements on the part of population, among others.

The company went into operation on June 18, 2010 and the facility is reflecting on various environmental problems such as the expulsion of 75 families the Movimento dos Sem Terra (MST) and the creation of an area of exclusion of fishing in a region it has economic activities such as fishing and tourism.

With the installation of the ventures provided for in the region: the new power plants Steel Company of the Atlantic (CSA) and the National Steel Company (CSN), the State of Rio de January will be the largest steel producer in the country and one of the largest in Latin America.

\section{Implantação da Companhia Siderúrgica do Atlântico na Baía de Sepetiba}

Segundo a Fundação CIDE atualmente o estado produz 7,9 milhões de aço bruto anualmente, passará a produzir 15,9 milhões, ultrapassando a produção de 11,7 milhões de toneladas do Estado de Minas Gerais. Segundo Ranulfo Vidigal ex-diretor da Fundação CIDE as novas usinas CSA e CSN significará um salto na siderurgia fluminense. Ele estima que o Produto Interno Bruto do setor, no Estado do Rio de Janeiro no ano de 2006 seja $R \$ 7,5$ bilhões.

A implantação da Companhia Siderúrgica do Atlântico consiste num grande projeto de investimento. Segundo Vainer os grandes projetos de investimentos são empreendimentos que movimentam abundantes investimentos; necessitam de muita mão-de-obra e que se destacam por ter dimensões significativas, como a siderúrgica. Esses investimentos em geral buscam atender a duas exigências: a de produção e reprodução das condições gerais do processo de acumulação e o ordenamento territorial.

"Em que consiste a base fundamental das metodologias que seguem o citado enfoque reducionista realista? Em geral, consagra-se a calcular - quando se trata de estimar o impacto ambiental, social ou econômico na região - os custos e benefícios quantificáveis associados à implantação do projeto. Se a relação benefício-custo, do ponto de vista quantitativo, resulta altamente positiva, isto vem apoiar a argumentação favorável à realização ou financiamento da obra (...) na maioria das avaliações de projetos de investimentos somente se leva em consideração a rentabilidade do capital incorporado mediante técnicas e critérios exclusivamente contábeis (Roffman \& Simone, 1988, p.5)." 


\section{REVISTA TAMOIOS}

Durante a etapa das obras civis o número de empregos é em geral inferior à aglomeração de trabalhadores, resultante pelo afluxo migratório que a expectativa induz. Muitos trabalhadores diante da oferta de trabalho, mesmo em situações em que o mercado de trabalho está em equilíbrio, abandonam suas ocupações anteriores-principalmente no setor agropecuário. Diante da possibilidade de maior renumeração e garantias trabalhistas superiores. Porém no momento que a etapa da construção civil termina, desmobiliza a maior parte do contingente de mão-de-obra, principalmente não qualificada, transformando a região num bolsão de desemprego (Araújo e Vainer 1992).

Os núcleos urbanos próximos a esses empreendimentos, depois da construção civil, os núcleos se deparam com a geração ou acentuação de processos comuns nos grandes núcleos urbanos, tais como favelização, marginalização, prostituição, criminalidade, mendicância, etc. Os espaços urbanos não estão devidamente equipados, mesmo quando a arrecadação aumenta - o que nem sempre ocorre devido a subsídios e benefícios fiscais oferecidos ás empresas, com a ilusão de que o empreendimento irá trazer desenvolvimento regional - os problemas acabam sendo multiplicados em ritmo e proporções maiores. As prefeituras, ou até mesmo governos estaduais, se deparam com o aumento de gastos com habitação, saneamento básico, transporte, educação, atendimento de saúde, segurança e infra-estrutura em geral.

Segundo Araújo e Vainer (1992) os grandes projetos acabam acentuando as disparidades regionais juntamente com a captura de periferias (recursos minerais, energéticos, etc.) realizada pelos centros hegemônicos nacionais e/ou internacionais. Cabendo as regiões de implantação, a desestruturação das atividades econômicas preexistentes, desemprego, favelização, crescimento desordenado da população, degradação ambiental, etc.

O setor industrial na região estudada começou a ser implementado nos anos 1960. Na década de 1970 houve a implantação da rodovia BR-101 e do Porto de Itaguaí. Nos anos 80, a região começou a apresentar altas taxas de crescimento demográfico resultante das atividades relacionadas ao Porto de Itaguaí e ao aumento da atividade turística gerando impacto sobre o meio ambiente.

A Companhia Siderúrgica do Atlântico é um conglomerado industrial, siderúrgico e portuário formado pela Companhia do Vale do Rio Doce que possui $27 \%$ enquanto que a ThyssenKrupp Steel empresa alemã detém 73\%. A capacidade produtiva será de 10 milhões de toneladas de placas de aço anual. 


\section{Terreno da Companhia Siderúrgica do Atlântico}

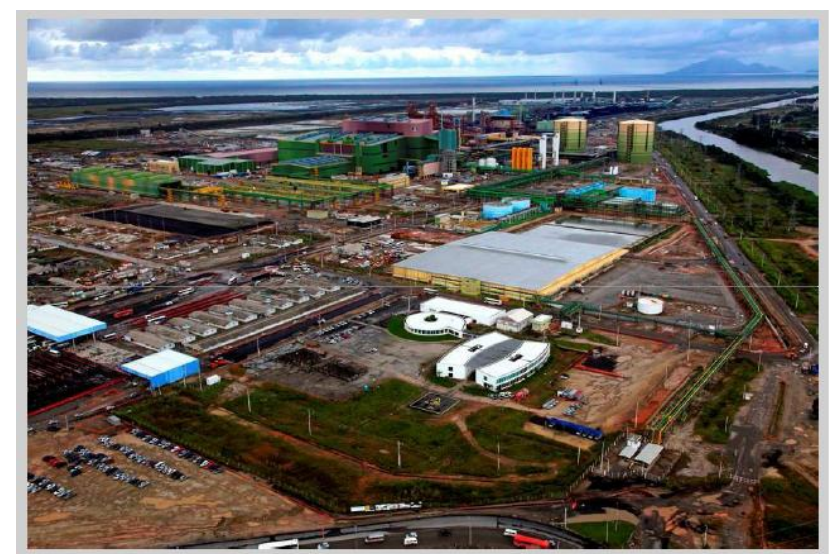

Foto 1 Fonte: http://www.thyssenkrupp-csa.com.br/index2.htm

O empreendimento está localizado na porção oeste do município do Rio de Janeiro, na região administrativa de Santa Cruz e próximo do Porto de Itaguaí. Na parte norte e leste limita-se com o continente, oeste com a Baía da llha Grande (Angra dos Reis) e sul com a Restinga de Marambaia (Itaguaí e Mangaratiba). A CSA é a maior siderúrgica da América Latina e sua área corresponde à área a duas vezes de dois bairros do município do Rio de Janeiro - Ipanema e Leblon.

\section{Localização dos Principais Investimentos do Estado do Rio de Janeiro}

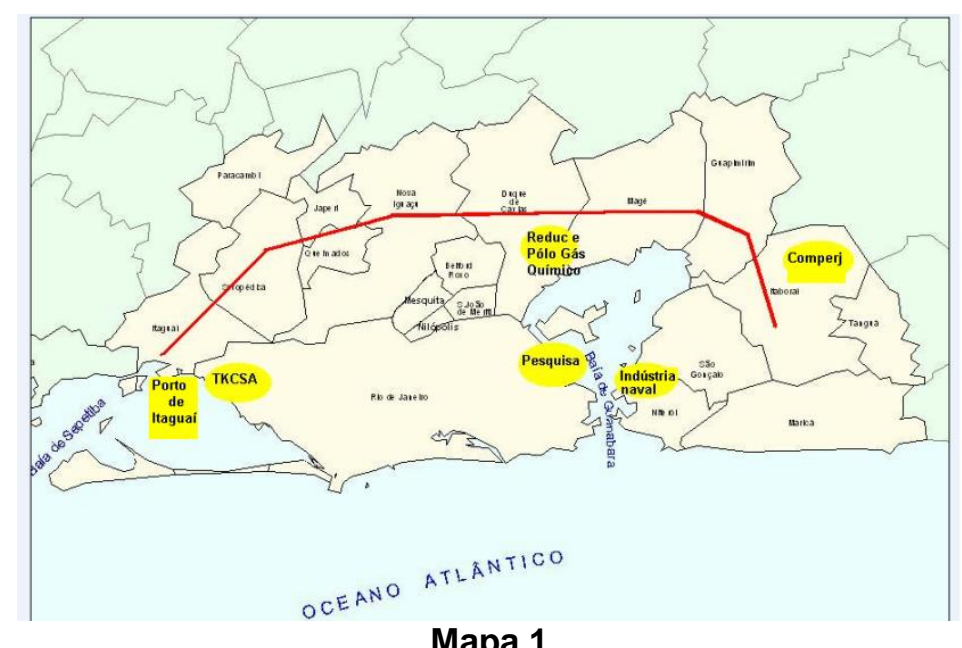

A porção oeste da região metropolitana onde a empresa está instalada apresenta intenso dinamismo. A região conta com diversos empreendimentos em fase de licenciamento da atividade portuária e siderúrgica: Portuário (Porto Sudeste da LLX Logística), cuja previsão é de escoar 50 milhões de toneladas de minério proveniente do Quadrilátero Ferrífero; ampliação do Porto de Itaguaí; construção de estaleiro de grande porte com a finalidade de construção de submarinos da Marinha do Brasil e de um porto que será compartilhado pelas empresas Companhia Siderúrgica Nacional (CSN), Gerdau e a Petrobras. No setor Siderúrgico o projeto é expandir a capacidade produtiva da Gerdau Cosigua e a implementação de uma 
nova usina da Gerdau voltada para a produção de aços especiais, cujo nome será Gerdau Aços Especiais Rio.

Nos últimos anos a região vem ganhando maior importância devido sua vantagem logística com a sucessiva implantação de projetos portuários e siderúrgicos. A região administrativa de Santa Cruz possui dois pólos importantes industriais, Palmares e Paciência, e encontrado empresas como Casa da Moeda, COSIGUA (Companhia Siderúrgica da Guanabara), VALESUL Alumínio S.A e a White Martins.

A planta da CSA se encontra próxima de um dos locais com maior potencial turístico do estado do Rio de Janeiro a Região da Costa Verde composta pelos municípios de Itaguaí, Mangaratiba, Angra dos Reis e Paraty. A região é ainda hoje entendida como pólo industrial, embora o Plano Estratégico da cidade do Rio de Janeiro seja fomentar o ecoturismo, principalmente na gastronomia, botânica, pesqueira e agrícola e a consolidação das diferentes expressões histórico-culturais da região. A atividade turística é impulsionada em razão da presença de ecossistemas ainda preservados.

Segundo a Fundação CIDE, os empreendimentos serão positivos para o mercado de trabalho. De acordo com as expectativas a Companhia Siderúrgica do Atlântico representará um acréscimo de $35 \%$ no emprego formal no setor siderúrgico no Estado do Rio de Janeiro.

Esta empresa representa apenas uma parte dos megaempreendimentos tanto em nível portuário e industrial projetado para a Baía de Sepetiba nas próximas décadas. A empresa representa um conglomerado industrial, siderúrgico e portuário da CSA. O conglomerado é constituído por: um porto com dois terminais juntamente como uma Ponte de Acesso com extensão de $4 \mathrm{~km}$ e um píer de 700 metros que atravessa o oceano e o manguezal; usina siderúrgica com capacidade produtiva de 10 milhões de toneladas de placas de aço e uma usina termoelétrica alimentada por quatro milhões de toneladas de carvão mineral oriundo da Colômbia com capacidade prevista de geração de 490MW de energia elétrica.

Com a instalação das grandes empresas haverá aumento da movimentação de trens de carga e de caminhões que transportarão minérios e além da logística marítima através de navios de grande porte, isso gerará poluição podendo dificultar a atividade turística e também impactará na vida e cultura das populações locais.

Quanto à logística ferroviária a empresa MRS Logística, que opera as ferrovias no entorno do município de Itaguaí, pretende investir $R \$ 200$ milhões, principalmente em locomotivas e vagões, com a finalidade de atender ao aumento da demanda das novas siderúrgicas Companhia Siderúrgica do Atlântico e Companhia Siderúrgica Nacional.

A instalação da Companhia Siderúrgica do Atlântico (CSA) e a Companhia Siderúrgica Nacional (CSN) devem gerar cerca de 70 mil empregos diretos e indiretos. As instalações irão produzir aço a partir do minério de ferro oriundo do estado de Minas Gerais. Estes empreendimentos possuem necessidade de desatar nós logísticos nas áreas portuária, ferroviária e rodoviária.

A Companhia Siderúrgica do Atlântico, com o objetivo de solucionar a logística do projeto, está construindo um porto próprio no meio da Baía de Sepetiba, ligado a parte terrestre através de uma ponte de quatro quilômetros. Apenas o terminal irá consumir US $\$ 700$ milhões dos $€ 5$ bilhões previstos para o projeto. Para a instalação do porto foi necessário realizar dragagem na área que resultou no revolvimento do lodo tóxico produzido durante anos pela Companhia Industrial Ingá, 
empresa que faliu no ano de 1998. Com a instalação do porto aumentou o tráfego de navios, o que desencadeou numa área exclusiva para a pesca.

\section{Aspectos Ambientais}

A Baía de Sepetiba foi declarada Área de Proteção Ambiental (APA) no dia 17 de junho de 1986. Na região possui importantes ecossistemas na sua área de abrangência, tais como floresta, restinga (Marambaia), manguezais e áreas remanescentes da Mata Atlântica com destaque para a Serra do Mar. Abriga espécies endêmicas e ameaçadas de extinção com áreas que servem de refúgio para aves costeiras. A Baía de Sepetiba, local da instalação do Complexo Siderúrgico possui $43 \mathrm{~km}$ de comprimento e de largura é $17 \mathrm{~km}$ no sentido norte-sul, com perímetro de $123 \mathrm{~km}$ e profundidade de seis metros em média.

As atividades econômicas dos municípios que integram a Baía estão pautadas em atividades de pesca (artesanal, industrial e maricultura) e do turismo. No aspecto social e cultural são encontradas comunidades quilombolas, índios, pescadores artesanais e caiçaras que preservam suas tradições culturais conferindo diversificado patrimônio social e cultural.

\section{Irregularidades na Instalação e no Funcionamento da Companhia}

A instalação da empresa e o funcionamento da mesma foram constatados diversas irregularidades como duplo padrão conforme foi constatado no parecer da Fiocruz e o licenciamento ambiental foi realizado de forma irregular.

No parecer da Fiocruz (Firpo \& Milanez, 2009¹) os técnicos responsáveis apontaram para o duplo padrão (conceito que descreve estratégia que as empresas transnacionais adotam padrões de segurança e legislação ambiental inferiores ao regulamentado no país de origem da transnacional). No parecer são apontados dois indícios que a empresa estaria se beneficiando da vulnerabilidade da legislação ambiental, adotando práticas que seriam questionáveis frente à legislação européia.

O projeto foi licenciando pelo órgão estadual Feema (Fundação Estadual de Engenharia do Meio Ambiente). Portanto possui ilegalidade quanto ao seu licenciamento, pois o EIA-RIMA (Estudo e Relatório de Impacto Ambiental) da empresa violou a Lei Federal No. 7661/88 e também o Decreto de regulamentação No. 5.300/2004 (Gerenciamento Costeiro), que estipula que o licenciamento de empreendimentos na zona costeira seja realizado apenas pelo órgão ambiental federal o IBAMA (Instituto Brasileiro do Meio Ambiente e dos Recursos Naturais Renováveis).

O processo de licenciamento não levou em consideração a articulação com o ambiente e outros empreendimentos que estão no seu entorno, resultando numa "minimização dos impactos ambientais".

O primeiro indício do duplo padrão é referente ao processo de licenciamento ambiental. Na União Européia, a empresa precisa incluir uma descrição do tipo e do volume das emissões previsíveis para os diferentes meios físicos e os efeitos no meio ambiente. Esses dados têm que ser tornar públicos no momento do licenciamento com a finalidade de serem debatidos pela união pública. Porém no Brasil o licenciamento ambiental não é construído de forma que a população possa participar. 
O segundo indício é referente à concentração de poluentes emitidos pela siderúrgica. No bairro de Santa Cruz a qualidade do ar apresenta qualidade inferior recomendada pelos países europeus. Dificilmente uma indústria deste porte na Europa seria instalada em ambientes já degradados como o bairro de Santa Cruz. Com o início da operação da empresa, a emissão de poluentes está agravando a qualidade do ar, conforme denúncias relatadas em grande jornal de circulação.

Segundo os técnicos responsáveis pelo Parecer da Fiocruz, os diferentes componentes do processo produtivo precisam ser analisados de forma integrada porque: a exposição das pessoas aos poluentes atmosféricos, ocorre de modo simultâneo e cumulativo; a possibilidade de processos de reação no meio ambiente das diversas substâncias.

\section{Papel do Estado na Implementação de Grandes Projetos de Investimento}

O Estado nas três esferas (municipal, estadual e federal) promove incentivos fiscais e concede subsídios para as empresas se instalarem na região e possui papel omisso quanto à fiscalização e respeito à legislação ambiental.

O Estado atua como interventor na facilitação da instalação de empreendimentos em áreas carentes de infra-estrutura. Ausenta-se na fiscalização das obras e flexibiliza a legislação. Atua de forma concentradora e excludente na implementação desses empreendimentos, pois beneficia algumas áreas com investimentos em detrimento de outras.

O Estado favorece os grandes empreendimentos a partir de incentivos fiscais, para o empreendimento está prevista isenção de ICMS (Imposto sobre Circulação de Mercadorias e Serviços) pelo período de 12 anos, correspondendo a uma diminuição de arrecadação na ordem US $\$ 150$ milhões por ano e redução de ISS (Imposto sobre Serviço de qualquer Natureza) pelo período de cinco anos. Também na aplicação de recursos públicos através de financiamento como o BNDES (Banco Nacional de Desenvolvimento Econômico e Social) na ordem de R\$1,48 bilhões. $O$ terreno onde o empreendimento está localizado foi concedido pelo Governo Federal. Em contrapartida a empresa fica responsável pela geração de empregos e a promoção e capacitação profissional nos níveis básico, médio e superior o previsto deveria atender por ano cerca de 500 pessoas da região da Baía de Sepetiba. Outra exigência foi à destinação de $25 \%$ do valor economizado proveniente da isenção para a construção de um Plano Diretor do entorno, prevendo o aumento populacional que o empreendimento ocasionaria, e a ajuda na recuperação da Baía de Sepetiba.

\section{Resultados Alcançados}

Os Grandes Projetos de Investimentos como o complexo siderúrgico que está sendo instalado na região administrativa de Santa Cruz, são empreendimentos que movimentam abundantes investimentos, que precisa de muita mão-de-obra e que se destacam por ter dimensões significativas.

A pesquisa encontra-se em fase de andamento. Foram avaliados os dados econômicos e a conjuntura da instalação da Companhia Siderúrgica do Atlântico e impactos na região da instalação: como criação de uma zona de exclusão de pesca; 
remoção de famílias que praticavam atividade agrícola; a produção flexível implementada na siderúrgica resultando em forte terceirização, entre outros.

O terreno onde está alocado à siderúrgica havia setenta e cinco famílias (75) ligadas ao MST (Movimento dos Trabalhadores Rurais Sem Terra) que estavam acampadas há cinco anos e retiravam seu sustento através da produção agrícola. Essas famílias foram expulsas e muitas delas foram para locais distantes e sem receber nenhuma indenização. Segundo jornais essas famílias estão provisoriamente assentadas numa fazenda na área do Tinguá, em volta da Reserva do Tinguá no município de Nova Iguaçu na Baixada Fluminense.

A questão concernente aos direitos trabalhistas, consta ações no Ministério Público do Trabalho devido à violação dos direitos trabalhistas. A empresa terceirizou muitos serviços para a construção do empreendimento, muitos trabalhadores oriundos de outras regiões do país como a Região Nordeste trabalharam como obreiros. Essa estratégia foi utilizada para evitar o vínculo empregatício às empresas empreiteiras contratam os trabalhadores por um prazo geralmente de três meses, resultando na precarização do trabalho. Um dos agravantes dessa vinda é que geralmente não é feita com nenhum planejamento por parte da esfera municipal resultando no aumento demográfico o que gera sobrecarga nos recursos naturais e acentuam os processos de favelização, aumento dos preços de alugueis e imóveis e aumento da demanda por serviços públicos tais como educação, saúde e previdência.

A empresa como estratégia de redução do custo de produção ao invés de oferecer emprego para a população local está contratando nordestinos e imigrantes como chineses que muitos estão ilegais no país, isentando a empresa do pagamento de impostos. A empresa desde o início da obra por meio de contrato realizado entre Thyssen Krupp e a China International Trust \& Investment Corporation (Citic) para vinda de 3.000 chineses aproveitando-se do baixo custo da mão de obra.

A instalação da empresa alterou a atividade econômica de 8.070 pescadores artesanais e de boa parte da população local que praticava o comércio. A expectativa de geração de empregos era de 18 mil empregos durante a construção e 3.500 empregos durante a fase de operacionalização, ou seja, após a instalação da empresa. Em outubro do ano de 2009 a empresa já reduziu a expectativa de empregos diretos para 2.500.

Diversas atividades que o empreendimento realizou tais como dragagem juntamente com aumento da circulação de navios na Baía de Sepetiba e nos canais resultando numa zona de exclusão para a atividade pesqueira e a contaminação das águas e dos peixes devido presença de metais pesados como Cadmo e Zinco, decorrente do vazamento da empresa Ingá Mercantil há cerca de 20 anos atrás, com a dragagem esses metais que estavam assentados no fundo oceânico foram revolvidos.

Segundo o biólogo Antônio Gomes da Fundação Instituto de Pesca do Estado do Rio de Janeiro (FIPERJ), em reportagem ao jornal O Dia do dia 31 de maio do ano de 2008, já teriam sido encontrados na região, peixes com deformações. Estas deformações poderiam ter relação com o grau de contaminação das águas pelos metais pesados.

O aumento da movimentação dos navios gerou zonas de exclusão (áreas que por motivos de segurança a atividade pesqueira é proibida), tendo impacto econômico na atividade pesqueira e a contaminação através de óleos etc, provocando a mortandade de peixes. Com a instalação do empreendimento ocorreu aumento populacional de bairros no entorno da siderúrgica diante da possibilidade 


\section{REVISTA TAMOIOS}

de emprego sendo que as áreas não possuem infra-estrutura para o contingente populacional.

A termelétrica a carvão mineral para a geração de 490 Megawatts de energia elétrica e a unidade de produção de cimento são as unidades que possuem maior efeito potencial sobre a saúde da população e o meio ambiente. Tanto a termelétrica e a cimenteira consome enormes quantidades de água, podendo prejudicar o abastecimento de água na região, principalmente durante o verão.No mês de janeiro do ano de 2010 vários dias houve a interrupção de abastecimento de água durante o período diurno e de noite o abastecimento era parcialmente normalizado.

\section{Notas}

1- arecer Técnico sobre o Relatório de Impacto Ambiental da Usina Siderúrgica do Atlântico (TKCSA), elaborado por Bruno Milanez e Marcelo Firpo Porto, pesquisadores do Centro de Estudos da Saúde do Trabalhador e Ecologia Humana da Escola Nacional de Saúde Pública Sérgio Arouca, da Fundação Oswaldo, Cruz, de julho de 2009.

\section{Bibliografia}

ARAUJO, Frederico e VAINER, Carlos. Grandes Projetos hidrelétricos e desenvolvimento regional. Centro Ecumênico de Documentação e Informação, Rio de Janeiro, setembro de 1992.

FUNDAÇÃO CIDE, Anuário Estatístico. Rio de Janeiro: 2004.

LIMONAD, Ester. Os Lugares da Urbanização. Tese de doutorado FAU/ USP. São Paulo, 1996.

OLIVEIRA, Floriano Godinho de. Reestruturação produtiva e regionalização da economia no território fluminense. Tese de doutorado FFCHL/USP. São Paulo, 2003. ROFFMAN, Alexandro e SIMONE, Cristina. Estructura socio-económica regional y grandes inversiones. Precisones metodológicas del processo de evaluación, CEUR/COESU, mimeo, 1988.

TERRITÓRIO. Rio de Janeiro, Fundação CIDE, 1997. 